\title{
Socio-Demographic Determinants Associated with Blastocystis Infection in Arequipa, Peru
}

\author{
Renzo S. Salazar-Sánchez, ${ }^{1,2 \star}$ Kasandra Ascuña-Durand, ${ }^{1}$ Jorge Ballón-Echegaray, ${ }^{3}$ Victor Vásquez-Huerta, ${ }^{3}$ \\ Elí Martínez-Barrios, ${ }^{3}$ and Ricardo Castillo-Neyra ${ }^{2,4}$ \\ ${ }^{1}$ Laboratorio de Microbiología Molecular, Facultad de Medicina, Universidad Nacional de San Agustín, Arequipa, Peru; ${ }^{2}$ One Health Unit, Zoonotic \\ Disease Research Lab, School of Public Health and Administration, Universidad Peruana Cayetano Heredia, Lima, Peru; ${ }^{3}$ Departamento de \\ Microbiología y Patología, Facultad de Medicina, Universidad Nacional de San Agustín, Arequipa, Peru; ${ }^{4}$ Department of Biostatistics, \\ Epidemiology and Informatics, Perelman School of Medicine of the University of Pennsylvania, Philadelphia, Pennsylvania
}

\begin{abstract}
Blastocystis is one of the most common protozoa in the human gut and a zoonotic organism related to unsanitary living conditions. This protozoon shows a broad distribution, unclear symptomatology, and undefined pathogenicity. In Peru, studies report the presence of Blastocystis in many regions, but the highest prevalence levels are reported in Arequipa. The aim of this study was to link Blastocystis infection with social determinants of health. We recruited and surveyed 232 infected and uninfected participants from houses with at least one Blastocystis-infected person. All samples were concentrated by spin concentration method in saline solution, examined by wet mount under light microscopy and confirmed with methylene-stained stool smear. We found a human Blastocystis prevalence of $51.3 \%$ in the study sample. We also found statistical associations between Blastocystis infection and peri-urban location in the city as well as the use of alternative non-domiciliary water supplies, suggesting these are risk factors for human Blastocystis infection.
\end{abstract}

\section{INTRODUCTION}

Intestinal parasitic infections are one of the most common public health problems, affecting more than two million people around the world. ${ }^{1,2}$ They are mainly found in areas with poor health and sanitary conditions, limited access to safe drinking water, inadequate disposal of human feces, ${ }^{3,4}$ and low levels of access to healthcare facilities. ${ }^{5}$ Among many helminths and protozoa with the potential to inhabit the human gut, Blastocystis is one of the most commonly identified organisms during stool examination. ${ }^{6}$

Blastocystis has a worldwide distribution and is the most commonly isolated microorganism in parasitological surveys. ${ }^{6}$ Despite being so ubiquitous and being discovered more than a 100 years ago, ${ }^{7}$ little is known about their pathogenicity, genetic diversity, transmission dynamics (including zoonotic and zooanthroponotic transmission), therapeutic options, and treatment efficacy. ${ }^{8,9}$ The role of Blastocystis in human disease remains controversial. ${ }^{10}$ Its presence in symptomatic and asymptomatic patients is difficult to explain; therefore, some report it as a pathogen, whereas others regard it as a commensal. ${ }^{11,12}$

Many risk factors are associated with Blastocystis infection, including to be 6 - or 7 -year-old child, ${ }^{13}$ male, ${ }^{14,15}$ and flooding of the home. The use of a latrine as compared with flush toilets is also associated with Blastocystis infection likely because of its relation to poor hygiene, ${ }^{14,16}$ water-borne transmission, and the lack of access to treated drinking water. ${ }^{16,17}$ By contrast, other studies mentioned that sociodemographic factors such as age, gender, water quality, disposition of excreta, place of residence, number of children in the house, monthly income, type of property, floor type, wall type, availability of public services, handwashing habits, and garbage disposal were not associated with Blastocystis infection. ${ }^{18}$ Domestic and wild animals are considered an important

\footnotetext{
* Address correspondence to Renzo S. Salazar-Sánchez, Laboratorio de Microbiología Molecular, Facultad de Medicina, Universidad Nacional de San Agustín, Av. Daniel Alcides Carrión S/N, Arequipa
} 04000, Peru. E-mails: rendaths@gmail.com or jballone@unsa.edu.pe source of Blastocystis transmission. ${ }^{8,18}$ However, previous studies suggest that livestock animals are not the main contributor of human infections. ${ }^{19}$ Carnivores, reptiles, and insects do not seem to be important sources of infection either. ${ }^{18}$

Most of these risk factor studies have been conducted in Asia and Europe, with few studies focusing on Latin American countries. In Peru, the presence of Blastocystis has been reported in many regions, mainly in parasitological surveys carried out in schoolchildren. ${ }^{20-22}$ The most common association with Blastocystis infection reported among positive study sites was poor sanitary conditions. ${ }^{23,24}$ Among the 24 regions in Peru, the highest prevalence has been reported in Arequipa. ${ }^{23}$ These previous studies did not aim to find factors associated with the high prevalence of infection in Arequipa or evidence of their association with symptomatology and gastrointestinal illnesses in infected cases.

Because of Blastocystis' disputed role as a pathogenic agent and the scarcity of Peruvian studies on factors associated with infection and symptomatology, this study aimed to identify individual and household-level factors associated with Blastocystis infections, and to add new evidence for the understanding of the complex epidemiology of this controversial intestinal protozoon. We studied Blastocystis infection in humans and animals across different levels of urbanization in Arequipa, Peru, which represents one of the first attempts in the region to apply the One Health approach to this microorganism. One Health is an approach that recognizes the connection among human, animal, and environmental health. ${ }^{25}$

\section{MATERIALS AND METHODS}

Ethical statement. The Institutional Review Boards of the Universidad Peruana Cayetano Heredia approved the protocol of this study, identification number 18006. Before collecting any data, all participants provided written informed consent. Minors provided verbal and/or written informed assent, and their parents provided written informed consent. We included participants from any age who were not taking any antimicrobial or antiparasitic treatment at the time of stool 
sample collection or the prior 7 days. All participants completed an epidemiological survey to assess clinical and sanitary living conditions. Participants' questions were solved at any moment.

Study site. This study was conducted in Arequipa city, which is located in the south highlands with a population size around a million people. ${ }^{26}$ Arequipa city comprises peri-urban and urban areas, which have distinct migration histories, and continuous growth from the center to the periphery. ${ }^{27}$ In the context of this centrifugal expansion, the peri-urban communities are younger than the urban communities and are farther from the center of the city. ${ }^{27}$ There are also social differences between the two types of communities: peri-urban areas tend to have limited basic services such as electricity, water, sanitation, health, and education, whereas urban locations have all these services more readily available (Figure 1).

Study population and participants' selection. To identify research participants, we carried out two free parasitological screening campaigns. The first campaign was advertised on the radio (Radio Universidad Arequipa) and television (TV
UNSA) for 3 weeks in January 2019, inviting any resident of Arequipa to participate in the campaign. The collection of samples, analysis, and reporting of results occurred in the Molecular Microbiology Laboratory, Universidad Nacional de San Agustín de Arequipa in Peru between January and March of 2019. One hundred sixty-eight people participated in the parasitological screening campaign, 102 tested positive for Blastocystis infection, and 66 were negative. We invited all 168 participants to follow-up on their household members, 61 of the 102 Blastocystis-positive participants and 44 of the 66 Blastocystis-negative participants accepted the invitation, and their household members were contacted to participate in the study. Detailed information of participants of the campaigns and recruitment is included in Figure 2.

For the purpose of this study, index cases were defined as any Blastocystis-positive participant identified during the initial screening campaigns and negative cases who were negative to any intestinal protozoon and parasite. To recruit household members of index cases, we communicated by phone or in person with index cases or parents from index cases to coordinate a date for visiting their home. Then, we

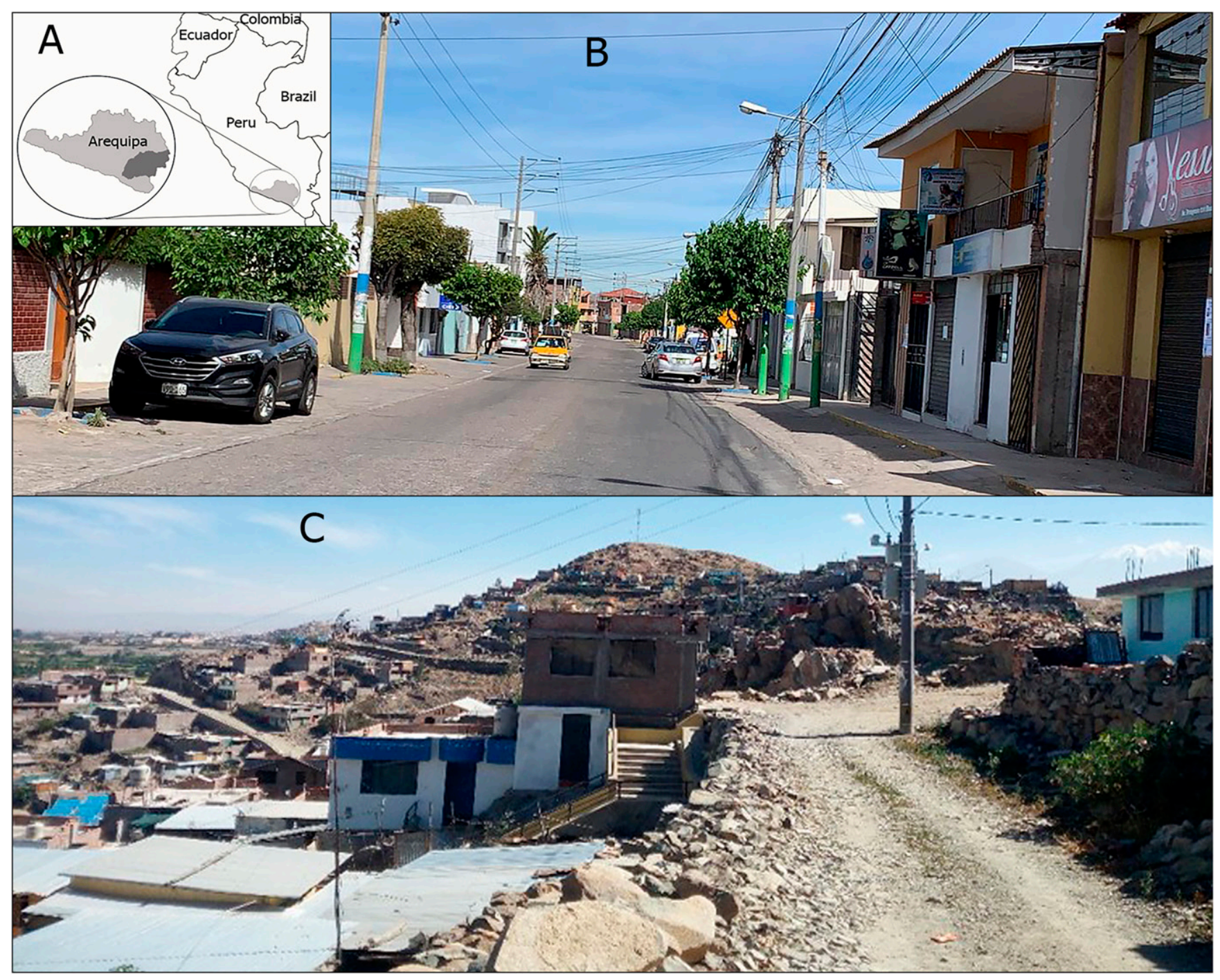

FIgure 1. Study site. (A) Map of Arequipa in Peru. (B) Urban locality with adequate sanitary conditions and access to public facilities. (C) Periurban locality with limited sanitary conditions. This figure appears in color at www.ajtmh.org. 


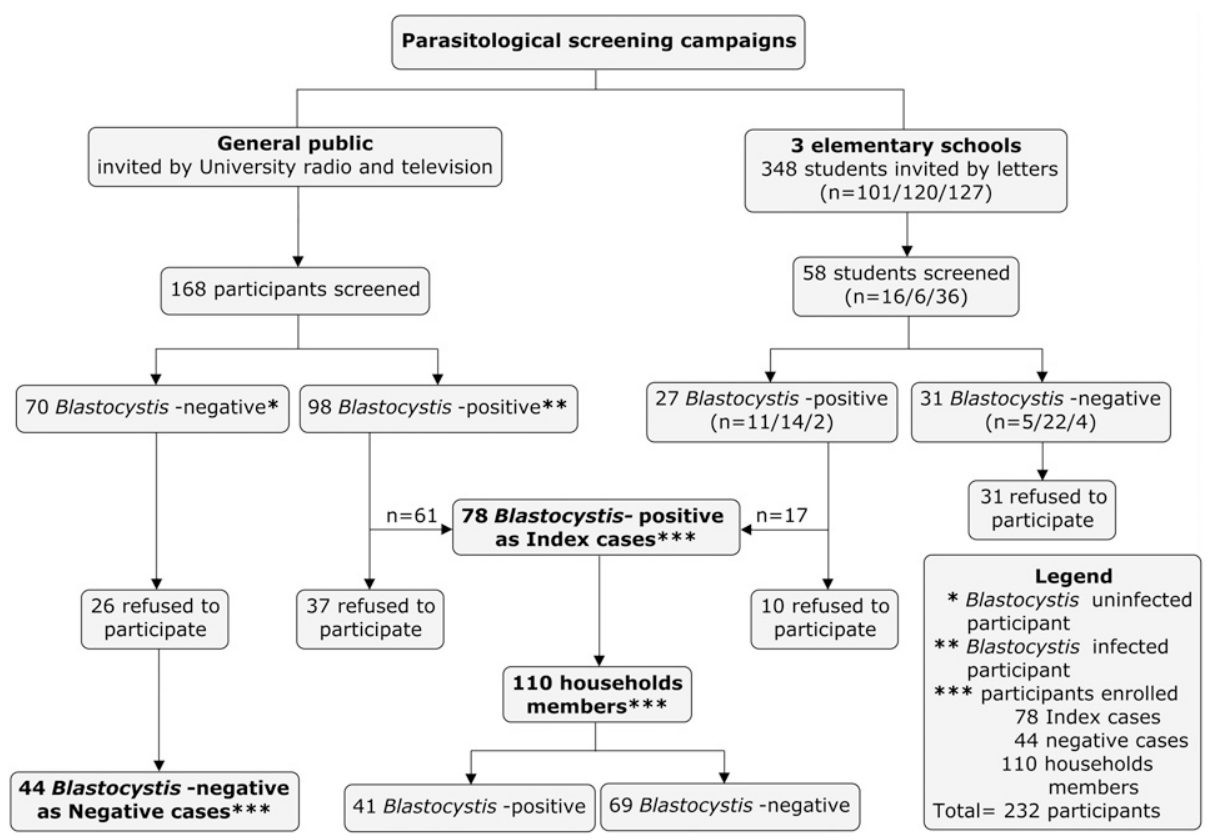

FIGURE 2. Diagram of recruitment campaigns and participant's enrollment and distribution.

invited household members to participate in the study with a free parasitological screening for them and their animals. All results were reported to participants in person 2 days after taking the stool sample. The research team medical doctor provided with antiparasitic treatment to people who were infected by any kind of intestinal protozoan.

Sample collection and laboratory diagnosis. All samples were collected by each participant in a sterilized plastic widemouth flask without additives. We instructed participants to avoid mixing with urine or water and wash hands with soap after collection. Instructions were given in person in a short letter.

To determine the presence of trophozoites and other protozoa stages, we applied a rapid spin concentration method with saline solution and examined the pellet with Lugol solution using a wet mount slide under light microscopy at $\times 400$ magnification. The results were confirmed with blue methylenestained stool smear at $\times 1,000$ magnification. ${ }^{28}$ All samples were aliquoted into cryovials and stored at $-80^{\circ} \mathrm{C}$.

Statistical analysis. Independent associations between Blastocystis infection and categorical demographic and sanitary conditions were analyzed with chi-square and Fisher's exact test. A multivariable logistic regression model was built to identify adjusted risk factors for Blastocystis infection. All analyses were performed using $R$ 3.6.2. ${ }^{29}$

\section{RESULTS}

We analyzed stool samples from 337 people and enrolled 232 participants during the campaigns. Participants were classified into 78 index cases, 110 household members (41 Blastocystis-positive and 69 Blastocystis-negative participants), and 44 negative cases. The age range of participants was $1-81$ years $($ mean $=37, S D=21.8)$, and the percentage of female participants was $55.6 \%(n=129)$. One hundred twentytwo participants are from urban locations, 101 from peri-urban locations, and nine came from rural areas. The education level of participants was 54 in elementary school, 44 high school, and 128 with college or advanced degrees. Professionally, our sample included 39 homemakers, 74 students, 42 employees, 66 independents contractors, and five retirees.

We identified seven species of intestinal protozoa, including two pathogenics. The prevalence of Blastocystis in the study sample was $51.3 \%$, with a coinfection percentage of $19 \%$. The second most prevalent protozoon was Entamoeba coli (19\%), as described in Figure 3. To explore the relationship between gastrointestinal symptomatology and Blastocystis infection, we included only participants with Blastocystis

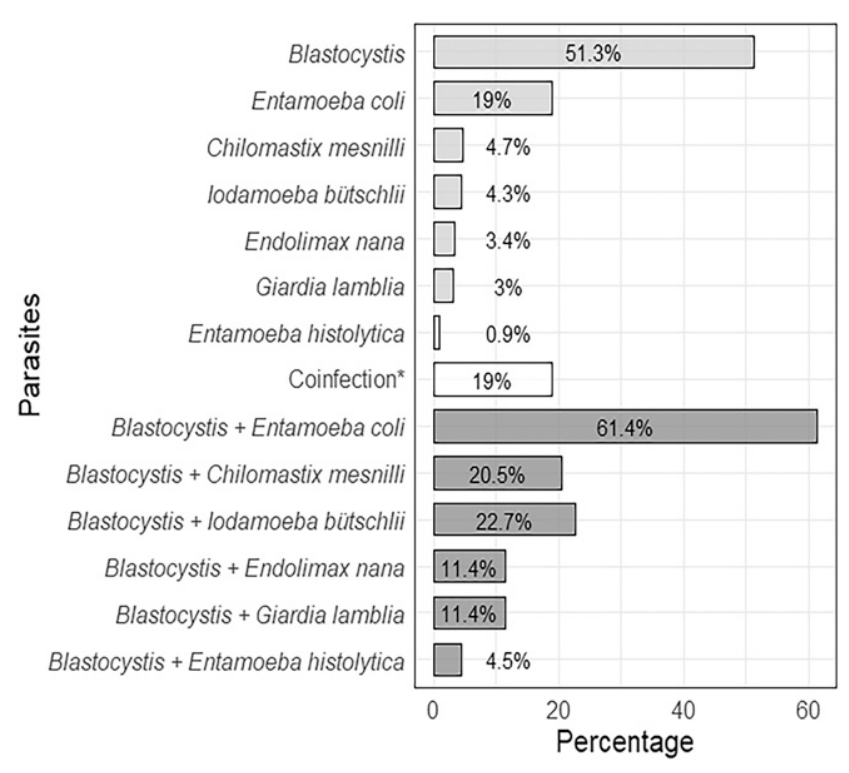

FIGURE 3. Percentage of intestinal parasites and Blastocystis coinfection in the study sample from Arequipa, Peru, in $2019(n=232)$. *Includes only Blastocystis coinfection with other parasites (Blastocystis coinfection in dark gray). 
single infection ( $n=46)$ and all participants who were negative to Blastocystis and any other protozoa and parasite $(n=65)$. Symptomatic participants showed no significant differences in Blastocystis prevalence (41.4\%) compared with asymptomatic participants (49.1\%). The two most frequent symptoms were flatulence and abdominal pain (44\% and 36\%), and the less frequent was irritable bowel syndrome (IBS) (5.3\%). Statistical analysis $(n=167)$ shows that symptomatology was not significantly different between Blastocystis-positive and Blastocystis-negative participants. Specific symptoms were also not significantly associated with Blastocystis infection (Table 1). We observed a higher percentage of Blastocystis infection in male participants across all age-groups, except in children younger than 5 years, and there was a positive trend of infection associated with age (Figure 4).

To set the statistical analysis for comparisons, we grouped our variables into sanitary variables and demographic variables, that include hygienic habits. The first group includes variables related to sanitary conditions such as location, water supply, body-waste disposal, presence of animals, and vectors. For all the analyses, we dropped participants from the rural location, and collapsed the water supply category into domiciliary tap water and other water supply that included public standpipe, water tank, and water well. Body-waste disposal was categorized into use of flush toilets and use of latrine, which also included silo (a basic and precarious latrine). Table 2 presents the statistical analysis for independent association of sanitary conditions, which was performed at the house level $(n=117)$, including houses from index cases and negative cases. We observed a higher percentage of Blastocystis infection in peri-urban areas than in urban areas $(P<$ $0.001)$. Also, there were significant associations among Blastocystis infection and body-waste disposal, and presence of rabbits and rodents. Other variables show no statistical association with Blastocystis infection in homes from index cases and negative controls.

The second group included variables related to demographic and hygienic habits of participants such as gender, age, education level, economic activity, food consumption place, kind of water consumption, handwashing habits, and cleanliness of hands and nails at the time of the survey. The economic activity represents participants' occupations, where different professions were identified and summarized as students, homemakers, employees, independent contractors, and retired. We

TABLE 1

Association between gastrointestinal symptoms and Blastocystis infection status

\begin{tabular}{|c|c|c|c|}
\hline \multirow[b]{3}{*}{ Variable } & \multicolumn{2}{|c|}{ Blastocystis infection, $n(\%)$} & \multirow[b]{3}{*}{$P$-value } \\
\hline & \multirow{2}{*}{$\frac{\text { Uninfected }}{(n=44)^{\star}}$} & \multirow{2}{*}{$\begin{array}{l}\text { Infected } \\
(n=73) \dagger\end{array}$} & \\
\hline & & & \\
\hline Abdominal pain & 36 (39.1) & $27(36.0)$ & $0.799 \ddagger$ \\
\hline Nausea and vomiting & $14(15.2)$ & $11(14.7)$ & $1 \ddagger$ \\
\hline Flatulence & $46(50.0)$ & $33(44.0)$ & $0.537 \ddagger$ \\
\hline Constipation & $28(30.4)$ & $16(21.3)$ & $0.25 \ddagger$ \\
\hline Diarrhea & $27(29.3)$ & $17(22.7)$ & $0.425 \ddagger$ \\
\hline IBS & $3(3.3)$ & $4(5.3)$ & $0.702 \S$ \\
\hline \multicolumn{4}{|c|}{$\begin{array}{l}{ }^{*} \text { Number of Blastocystis-uninfected participants includes } 44 \text { negative cases and } 21 \\
\text { household members with negative result to Blastocystis and any other protozoa and parasite } \\
\text { † Number of Blastocystis-infected participants corresponds to participants with Blasto- } \\
\text { cystis single infection. } \\
\text { †Chi-square test. } \\
\text { § Fisher's exact test. }\end{array}$} \\
\hline
\end{tabular}

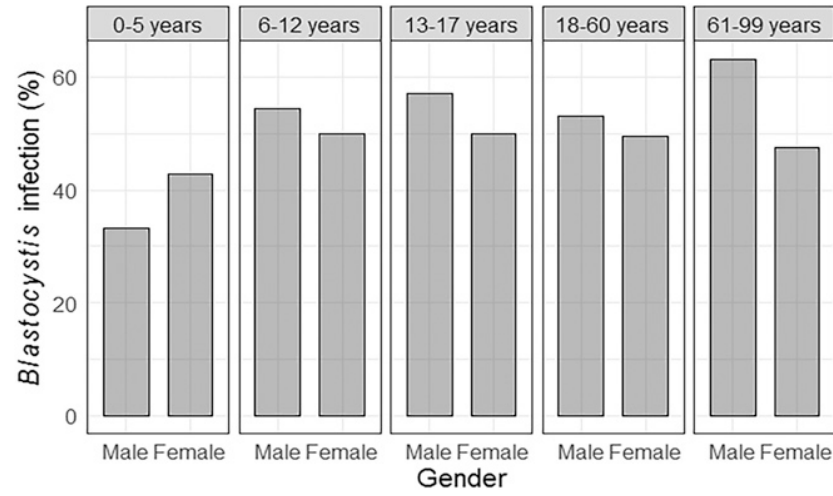

FIGURE 4. Percentage of Blastocystis infection associated with age and gender.

performed statistical analysis at the individual level $(n=155)$ with Blastocystis-infected and uninfected participants from houses with at least one Blastocystis-positive participant to determine intra-household factors associated with Blastocystis transmission. We do not include the few participants whose responses to hygienic habit questions were "sometimes." The outcome is presented in Table 3, where no variable shows a significant association with Blastocystis infection.

Bivariate analyse highlighted that location (odds ratio $[\mathrm{OR}]=$ $7.2)$, other water supply $(\mathrm{OR}=4.6)$, use of latrine $(\mathrm{OR}=6.8)$, and presence of rabbits $(O R=10.2)$ were statistically associated with Blastocystis infection. To set up the multivariate analysis, we included variables yielding a $P$-value less than or equal to 0.2 in the bivariate analysis and performed a stepwise approach to determine interaction and effect of independent variables on Blastocystis infection. Multivariate analysis showed that the only variables that affect Blastocystis infection were living in peri-urban areas $(\mathrm{OR}=3.7)$, having or using a different water

TABLE 2

Sanitary characteristics of houses from index cases (Blastocystis-infected participants) and negative cases (Blastocystis-uninfected participants)

\begin{tabular}{|c|c|c|c|}
\hline & Blastocysti & ction, $n(\%)$ & \\
\hline & Uninfected & Infected & \\
\hline Variable & $(n=44)^{*}$ & $(n=73) \dagger$ & $P$-value \\
\hline Location & & & \\
\hline Urban & $37(84.1)$ & $31(42.5)$ & $0.0001 \ddagger$ \\
\hline Peri-urban & 7 (15.9) & $42(57.5)$ & \\
\hline Water supply & & & \\
\hline Domiciliary tap water & $43(97.7)$ & $66(90.4)$ & $0.255 \S$ \\
\hline Other water supply & $1(2.3)$ & $7(9.6)$ & \\
\hline Body-waste disposal & & & \\
\hline Piped sewer system & $43(97.7)$ & $63(86.3)$ & $0.051 \neq$ \\
\hline Latrine & $1(2.3)$ & $10(13.7)$ & \\
\hline Presence of dog & $24(54.5)$ & $42(57.5)$ & $0.902 \ddagger$ \\
\hline Presence of cat & $10(22.7)$ & $24(32.9)$ & $0.337 \ddagger$ \\
\hline Presence of guinea pig & 8 (18.2) & $17(23.3)$ & $0.675 \ddagger$ \\
\hline Presence of rabbit & $1(2.3)$ & 14 (19.2) & $0.018 \ddagger$ \\
\hline Presence of poultry & $11(25.0)$ & $18(24.7)$ & $1 \neq$ \\
\hline Presence of flies & $31(70.5)$ & $50(68.5)$ & $0.987 \ddagger$ \\
\hline Presence of cockroach & $6(13.6)$ & $16(21.9)$ & $0.386 \ddagger$ \\
\hline
\end{tabular}

Bolding highlights significant $P$-values.

${ }^{*} n$ corresponds to negative cases (participants with negative result to Blastocystis and any other protozoa and parasite).

$\dagger n$ corresponds to index cases (first Blastocystis-positive participant identified during the initial screening campaigns).

$\ddagger$ Chi-square test.

$\S$ Fisher's exact test. 
TABLE 3

Blastocystis infection status associated with characteristics of participants at individual level

\begin{tabular}{|c|c|c|c|}
\hline \multirow[b]{3}{*}{ Variable } & \multicolumn{2}{|c|}{ Blastocystis infection, ${ }^{*} n(\%)$} & \multirow[b]{3}{*}{$P$-value } \\
\hline & Uninfected & Infected & \\
\hline & $n=68$ & $n=87$ & \\
\hline \multicolumn{4}{|l|}{ Gender } \\
\hline Female & $42(61.8)$ & $44(50.6)$ & $0.219 \dagger$ \\
\hline \multicolumn{4}{|l|}{ Age-group (years) } \\
\hline $0-5$ & $4(5.9)$ & $4(4.6)$ & $0.815 \ddagger$ \\
\hline $6-12$ & $13(19.1)$ & $17(19.5)$ & \\
\hline $13-17$ & $4(5.9)$ & $6(6.9)$ & \\
\hline $18-60$ & $41(60.3)$ & $47(54.0)$ & \\
\hline $61-99$ & $6(8.8)$ & 13 (14.9) & \\
\hline \multicolumn{4}{|l|}{ Education level } \\
\hline Elementary & $17(25.8)$ & $21(24.7)$ & $0.918 \dagger$ \\
\hline High school & $17(25.8)$ & $20(23.5)$ & \\
\hline University & $32(48.5)$ & $44(51.8)$ & \\
\hline \multicolumn{4}{|l|}{ Economic activity } \\
\hline Student & $27(40.9)$ & $31(38.3)$ & $0.925 \dagger$ \\
\hline Homemaker & $11(16.7)$ & $13(16.0)$ & \\
\hline Employees & $8(12.1)$ & $13(16.0)$ & \\
\hline Independent contractor & $20(30.3)$ & $24(29.6)$ & \\
\hline \multicolumn{4}{|l|}{ Food consumption place } \\
\hline House & $45(66.2)$ & $61(70.1)$ & $0.636 \ddagger$ \\
\hline Restaurant & $1(1.5)$ & 0 & \\
\hline House and restaurant & $15(22.1)$ & $20(23.0)$ & \\
\hline House and kiosk & $7(10.3)$ & $6(6.9)$ & \\
\hline \multicolumn{4}{|l|}{ Kind of water consumption } \\
\hline Boiled water & $54(79.4)$ & 68 (78.2) & $1 \neq$ \\
\hline Tap water & $4(5.9)$ & $6(6.9)$ & \\
\hline Both & $10(14.7)$ & $13(14.9)$ & \\
\hline Do not wash hands after using bathroom & $6(8.8)$ & $7(8.0)$ & $1 \dagger$ \\
\hline Do not wash hands before cooking & $13(19.1)$ & $22(25.3)$ & $0.4727 \dagger$ \\
\hline Do not wash hands before eating & $11(16.7)$ & $9(10.5)$ & $0.3794 \dagger$ \\
\hline Do not wash hands after touching animals & $21(31.3)$ & $31(35.6)$ & $0.6994 \dagger$ \\
\hline Had dirty hands at the time of survey & $13(19.1)$ & $21(24.1)$ & $0.5796 \dagger$ \\
\hline Had dirty nails at the time of survey & $21(30.9)$ & $32(36.8)$ & $0.55 \dagger$ \\
\hline
\end{tabular}

* The analysis includes only index cases and their household members.

† Chi square test.

‡Fisher exact test.

supply than domiciliary tap water $(O R=19.3)$, and presence of dogs $(O R=10.2)$; the most significant association was with domiciliary water supply (Table 4). Other variables in the analysis showed no significant association with Blastocystis infection, mainly variables related to demographic and hygienic habits.

\section{DISCUSSION}

The controversy surrounding Blastocystis in recent decades has resulted in increased interest in developing detailed studies focused on determining whether or not the protozoon is pathogenic or beneficial to infected humans. ${ }^{9,30}$ Most previous studies in Arequipa focused on reporting intestinal parasites' prevalence in elementary schoolchildren. Those reports identified Blastocystis as a recurrent protozoon in this population, although they did not link epidemiological data to clinical outcomes. This is the first study that aimed to use the One Health approach to identify social determinants and individual factors associated with Blastocystis infection in Arequipa, Peru.

The prevalence of Blastocystis infection found in our study was similar to other values reported in previous studies in Peru. ${ }^{20-22}$ However, it was in the lower boundary of the range previously reported in Arequipa (48.3-81.9\%). ${ }^{23,24}$ This lower prevalence can be explained by the fact that previous studies in Arequipa were focused on schoolchildren, and we included all age-groups. We observed prevalence of Blastocystis infection above $50 \%$ in schoolchildren and lower values in people ages 60 years or older and infants. However, Blastocystis was the most prevalent protozoon in this study sample, which is similar to other studies around the world. ${ }^{31,32}$ Likewise, we found no significant difference in the infection rate according to age or gender, a trend which has been reported in other studies. ${ }^{33,34}$ Our results counter findings from rural populations of rural Honduras where age was associated with the amount of Blastocystis DNA detected. ${ }^{35}$ Also, in rural populations of Brazil, Blastocystis infection was linked to being female and being homemakers. ${ }^{15}$

This study highlights living in peri-urban communities as one of the most important risk factors for the transmission of Blastocystis in humans. This is supported by a WHO report on social determinants of health, ${ }^{36}$ which described how peri-urban areas often have unhealthy sanitary conditions linked to poverty that facilitate health problems and increase rates of infectious diseases. These conditions are quite similar to rural areas, the origin of local migration to peri-urban areas of Arequipa. ${ }^{37}$

We identified that water supply is the other main risk factor for Blastocystis transmission in peri-urban locations. Because 
TABLE 4

Bivariate and multivariate analysis of Blastocystis infection risk factors

\begin{tabular}{|c|c|c|c|c|c|c|}
\hline \multirow[b]{2}{*}{ Variable } & \multicolumn{3}{|c|}{ Bivariate logistic regression } & \multicolumn{3}{|c|}{ Multivariate logistic regression } \\
\hline & $\mathrm{OR}^{*}$ & $95 \% \mathrm{Cl}$ & $P$-value & OR† & $95 \% \mathrm{Cl}$ & $P$-value \\
\hline Peri-urban location & 7.2 & $3.0-19.5$ & $<0.001$ & 3.7 & $1.4-10.8$ & 0.012 \\
\hline Water supply: other water supply & 4.6 & $0.8-86.8$ & 0.101 & 19.3 & $1.5-425.2$ & 0.038 \\
\hline Body-waste disposal: latrine & 6.8 & $1.2-127.6$ & 0.024 & 0.1 & $0-0.8$ & 0.040 \\
\hline Presence of dog & 1.1 & $0.5-2.4$ & 0.752 & 10.2 & $2.0-59.7$ & 0.006 \\
\hline Presence of cat & 1.7 & $0.7-4.1$ & 0.236 & - & - & - \\
\hline Presence of guinea pig & 1.4 & $0.6-3.7$ & 0.511 & - & - & - \\
\hline Presence of rabbit & 10.2 & $1.9-188.4$ & 0.003 & 2.0 & $0.6-7.3$ & 0.258 \\
\hline Presence of poultry & 1.0 & $0.4-2.4$ & 0.967 & - & - & - \\
\hline Presence of flies & 0.9 & $0.4-2.0$ & 0.824 & - & - & - \\
\hline Presence of cockroach & 1.8 & $0.7-5.3$ & 0.258 & - & - & - \\
\hline Female participants & 0.6 & $0.3-1.2$ & 0.163 & 0.6 & $0.3-1.3$ & 0.178 \\
\hline \multicolumn{7}{|l|}{ Age-group (years) } \\
\hline $13-17$ & 1.5 & $0.2-10.4$ & 0.672 & - & - & - \\
\hline $18-60$ & 1.1 & $0.3-5.1$ & 0.853 & - & - & - \\
\hline $61-99$ & 2.2 & $0.4-12.4$ & 0.370 & - & - & - \\
\hline \multicolumn{7}{|l|}{ Education } \\
\hline High school & 1.0 & $0.4-2.4$ & 0.916 & - & - & - \\
\hline University & 1.1 & $0.5-2.4$ & 0.789 & - & - & - \\
\hline \multicolumn{7}{|l|}{ Food consumption place } \\
\hline House and restaurant & 1.0 & $0.5-2.2$ & 0.967 & - & - & - \\
\hline House and kiosk & 0.6 & $0.2-2.0$ & 0.437 & - & - & - \\
\hline \multicolumn{7}{|l|}{ Kind of water consumption } \\
\hline Tap water & 1.2 & $0.3-4.9$ & 0.794 & - & - & - \\
\hline Boiled and tap water & 1.0 & $0.4-2.6$ & 0.945 & - & - & - \\
\hline Do not wash hands after using bathroom & 1.1 & $0.3-3.5$ & 0.863 & - & - & - \\
\hline Do not wash hands before cooking & 0.7 & $0.3-1.5$ & 0.359 & - & - & - \\
\hline Do not wash hands before eating & 1.7 & $0.7-4.5$ & 0.265 & - & - & - \\
\hline Do not wash hands after touching animals & 0.8 & $0.4-1.6$ & 0.576 & - & - & - \\
\hline Had dirty hands at the time of survey & 1.3 & $0.6-3$ & 0.452 & - & - & - \\
\hline Had dirty nails at the time of survey & 1.3 & $0.7-2.6$ & 0.441 & - & - & - \\
\hline
\end{tabular}

Bolding highlights significant $P$-values.

*Unadjusted OR values.

† Adjusted OR values.

of the limited access to domiciliary tap water, people in periurban areas often consume water from standpipes, water tanks, or wells. Some studies have reported similar results, pointing to the lack of piped water and public sewage ${ }^{38}$; meanwhile, other studies were focused on areas with poor hygiene and sanitation, and facilities with a high prevalence of Blastocystis, ${ }^{14,39}$ whereas others studies did not find this association. ${ }^{40}$ Blastocystis has been reported in bodies of water in the veterinary literature ${ }^{39,41}$ and in contaminated water, which has been reported as a source of infection. ${ }^{13}$

The presence of animals is a common characteristic in peri-urban locations in Arequipa, where community members raise animals as a food resource, a rural custom brought to city because of migration. ${ }^{37}$ We found that the presence of dogs and rabbits is associated with Blastocystis infection in humans. This finding suggests that animals can play a key role in Blastocystis zoonotic transmission into infected homes and act as secondary reservoirs for Blastocystis. ${ }^{42}$ Furthermore, other studies in Latin America detected Blastocystis sp. in wild animal species, suggesting other cycles of transmission and potential reservoir species. ${ }^{43}$ Therefore, a One Health approach may be helpful in understanding the epidemiology of Blastocystis. This approach is also supported by previous studies that reported the occurrence of Blastocystis infection in different animal species such as poultry, cattle, pigs, and dogs. ${ }^{44,45}$ Similar associations to these animal species have been reported in endemic zoonotic disease in Arequipa. ${ }^{46}$

This study provides an overview sociodemographic determinant associated with Blastocystis infections; however, we could not determinate the commensal or pathogenic role of Blastocystis in humans. Some limitations of our study are the different procedures for participant recruitment and low participation in our campaigns. We were also unable to enroll all household members of every index case to estimate the household-level burden and potential factors associated with the level of infection within houses. It is also possible that the low response rate introduced selection bias in our study. Furthermore, our study design was crosssectional; therefore, it is possible that Blastocystis infection is transient and with a high rate of coinfection. Finally, the sampling we used for the university-based campaign was not random, and some of the variables we analyzed are correlated. Future studies would benefit from improved recruitment strategies, including rural areas, and conducting longitudinal studies in humans and their animals to assess changes in Blastocystis infection status and potential transmission pathways.

\section{CONCLUSION}

We found that human Blastocystis infection is associated with a group of factors that are found in peri-urban environments in the city of Arequipa, such as using an alternative not 
domiciliary water supply and using latrines for human waste body-waste disposal. The role of animals such as dogs and rabbits further elucidated to understand if they act as reservoirs or recipients of the protozoon (zooanthroponosis). We did not find a link between Blastocystis infection and gastrointestinal symptomatology in our study, so that, we cannot rule out the possibility that Blastocystis does have pathogenic potential, and they were not present in our study area or were present in very low frequencies.

Received June 9, 2020. Accepted for publication September 27, 2020. Published online November 16, 2020.

Acknowledgments: We thank Irmia Paz (UNSA) for her revision and suggestions, Julianna Shinnick for her valuable support and advice related to English review, and Cirilo Neyra for technical support. In addition, we gratefully thank the principals from the schools that participate in the study: Berardo Jesus Carrasco Castro, principal at Sagrado Corazón de Jesus 40078 Primary school from Tio Chico, Sachaca. Salome Eliana Alvarez Marquina, principal at Tío Chico Kinder garden school, Sachaca. Deysi Lilian Esquiagola Tapia, principal at Karol Jozef Wojtyla, primary school from Socabaya. We also thank the principal from Jose Carlos Echavarry Osacar, primary school from Tiabaya.

Financial support: We gratefully acknowledge financial support from the Universidad Nacional de San Agustín (UNSA) for the project "Morphological, Molecular and Clinical Diagnosis of Blastocystis as an emerging disease in humans and its association with the treatment and keeping of animals." Proyectos de Investigación Aplicada Inicial2017 Contrato IAI 002-2018-UNSA.

Authors' addresses: Renzo S. Salazar-Sánchez and Kasandra Ascuña-Durand, Laboratorio de Microbiología Molecular, Facultad de Medicina, Universidad Nacional de San Agustín, Arequipa, Peru, E-mails: rendaths@gmail.com and kasandra.asc@gmail.com. Jorge Ballón-Echegaray, Victor Vásquez-Huerta, and Elí Martínez-Barrios, Departamento de Microbiología y Patología, Facultad de Medicina, Universidad Nacional de San Agustín, Arequipa, Peru, E-mails: jballone@unsa.edu.pe, vvasquezh@unsa.edu.pe, and emartinezb@ unsa.edu.pe. Ricardo Castillo-Neyra, Department of Biostatistics, Epidemiology and Informatics, Perelman School of Medicine of the University of Pennsylvania, Philadelphia, PA, E-mail: cricardo@ pennmedicine.upenn.edu.

This is an open-access article distributed under the terms of the Creative Commons Attribution (CC-BY) License, which permits unrestricted use, distribution, and reproduction in any medium, provided the original author and source are credited.

\section{REFERENCES}

1. Alum A, Rubino JR, ljaz MK, 2010. The global war against intestinal parasites-should we use a holistic approach? Int $\mathrm{J}$ Infect Dis 14: e732-e738.

2. Torgerson PR et al., 2015. World Health Organization estimates of the global and regional disease burden of 11 Foodborne parasitic diseases, 2010: a data synthesis. PLoS Med 12: 1-22.

3. Efstratiou A, Ongerth JE, Karanis P, 2017. Waterborne transmission of protozoan parasites: review of worldwide outbreaksan update 2011-2016. Water Res 114: 14-22.

4. Fuhrimann S, Winkler MS, Kabatereine NB, Tukahebwa EM, Halage AA, Rutebemberwa E, Medlicott K, Schindler C, Utzinger J, Cissé G, 2016. Risk of intestinal parasitic infections in people with different exposures to wastewater and fecal sludge in Kampala, Uganda: a cross-sectional study. PLoS Negl Trop Dis 10: 1-19.

5. Curval LG, França ADO, Fernandes HJ, Mendes RP, De Carvalho LR, Higa MG, de Castro Ferreira E, Dorval MEC, 2017. Prevalence of intestinal parasites among inmates in Midwest Brazil. PLoS One 12: 1-14.

6. Ocaña-Losada C, Cuenca-Gómez JA, Cabezas-Fernández MT, Vázquez-Villegas J, Soriano-Pérez MJ, Cabeza-Barrera I,
Salas-Coronas J, 2018. Clinical and epidemiological characteristics of intestinal parasite infection by Blastocystis hominis. Rev Clín Esp 218: 115-120.

7. Stensvold CR, Suresh GK, Tan KSW, Thompson RCA, Traub RJ, Viscogliosi E, Yoshikawa H, Clark CG, 2007. Terminology for Blastocystis subtypes-a consensus. Trends Parasitol 23: 93-96.

8. Yoshikawa H, Tokoro M, Nagamoto T, Arayama S, Asih PBS, Rozi IE, Syafruddin D, 2016. Molecular survey of Blastocystis sp. from humans and associated animals in an Indonesian community with poor hygiene. Parasitol Int 65: 780-784.

9. Khademvatan S, Masjedizadeh R, Yousefi-Razin E, Mahbodfar $\mathrm{H}$ Rahim F, Yousefi E, Foroutan M, 2018. PCR-based molecular characterization of Blastocystis hominis subtypes in southwest of Iran. J Infect Public Health 11: 43-47.

10. Mohamed AM, Ahmed MA, Ahmed SA, Al-Semany SA, Alghamdi SS, Zaglool DA, 2017. Predominance and association risk of Blastocystis hominis subtype $\mathrm{i}$ in colorectal cancer: a case control study. Infect Agent Cancer 12: 1-8.

11. Eroglu F, Genc A, Elgun G, 2009. Identification of Blastocystis hominis isolates from asymptomatic and symptomatic patients by PCR. Parasitol Res 105: 1589-1592.

12. Chan $\mathrm{KH}$, Chandramathi $\mathrm{S}, 2012$. Effects of symptomatic and asymptomatic isolates of Blastocystis hominis on colorectal cancer cell line, HCT116. 110: 2475-2480.

13. Batchoun R, 1994. Intestinal colonization of symptomatic and asymptomatic schoolchildren with Blastocystis hominis 32 : 2865-2866.

14. Minvielle MC, Pezzani BC, Cordoba MA, De Luca MM, Apezteguia MC, Basualdo JA, 2004. Epidemiological survey of Giardia spp. and Blastocystis hominis in an argentinian rural community. Korean J Parasitol 42: 121-127.

15. Barbosa CV, Barreto MM, de Jesus Andrade R, Fernando Sodre C, Masini d'Avila-Levy C, Peralta JM, Igreja RP, de Macedo HW, Santos HLC, 2018. Intestinal parasite infections in a rural community of Rio de Janeiro (Brazil): prevalence and genetic diversity of Blastocystis subtypes. PLoS One 13: e0193860.

16. Leelayoova S, Siripattanapipong S, Thathaisong U, Naaglor T, Taamasri P, Piyaraj P, Mungthin M, 2008. Drinking water: a possible source of Blastocystis spp. subtype 1 infection in schoolchildren of a rural community in central Thailand. $A m \mathrm{~J}$ Trop Med Hyg 79: 401-406.

17. Abdulsalam AM, Ithoi I, Al-Mekhlafi HM, Ahmed A, Surin J, Mak JW, 2012. Drinking water is a significant predictor of Blastocystis infection among rural Malaysian primary schoolchildren. Parasitology 139: 1014-1020.

18. Cian A et al., 2017. Molecular epidemiology of Blastocystis sp. in various animal groups from two French zoos and evaluation of potential zoonotic risk. PLoS One 12: e0169659.

19. Alfellani MA, Taner-mulla D, Jacob AS, Atim C, Yoshikawa $H$, Stensvold CR, Clark CG, 2013. Genetic diversity of Blastocystis in livestock and zoo animals. Ann Anat 164: 497-509.

20. Ibáñez Herrera N, Jara CC, Guerra MA, Díaz Limay E, 2004. Prevalencia del enteroparasitismo en escolares de comunidades nativas del Alto Marañón, Amazonas, Perú. Rev Peru Med Exp Salud Publica 21: 126-133.

21. Sánchez L, Gallardo J, Jara C, 2011. Prevalencia de infección por Blastocystis y protozoarios intestinales en niños de "Alto Trujillo," La Libertad, Perú. Sciéndo 14: 36-45.

22. Marcos L, Maco V, TerashimaA, Samalvides F, Miranda E, GotuzzoE, 2003. Parasitosis intestinal en poblaciones urbana y rural en Sandia, Departamento de Puno, Perú. Parasitol Latinoam 58: 35-40.

23. Quispe C, Chiara Y, Moreno O, 2016. Elevada prevalencia de Blastocystis spp. en niños de una escuela periurbana. Fac Med 77: 393-396.

24. Casquina-Guere L, Martínez-Barrios E, 2011. Prevalencia y epidemiología del parasitismo intestinal en escolares de nivel primario de Pucchún, Camaná, Arequipa, Perú, 2006. Neotrop Helminthol 5: 1-9.

25. CDC, National Center for Emerging and Zoonotic Infectious Diseases (NCEZID), 2020. One Health. Available at: https:// www.cdc.gov/onehealth/index.html. Accessed September 3, 2020.

26. Instituto Nacional de Estadística e Informática-INEI, 2018. Censos Nacionales 2017: XII de Población, VII de Vivienda y 
III de Comunidades Indígenas. Available at: https://www.inei.gob.pe/ media/MenuRecursivo/publicaciones_digitales/Est/Lib1551/. Accessed April 11, 2020.

27. Levy MZ et al., 2014. Urbanization, land tenure security and vector-borne Chagas disease. Proc Biol Sci 281: 20141003

28. Bergamo do Bomfim TC, Carvalho MM, 2013. Morphological diagnosis and occurrence of Blastocystis spp. obtained from the stool samples of domestic bird species commercialized in municipal markets. J Parasitol Vector Biol 5: 20-26.

29. R Project. What is R? Available at: http://www.r-project.org/ about.html. Accessed November 25, 2019.

30. Andersen LOB, Bonde I, Nielsen HBHB, Stensvold CR, 2015. A retrospective metagenomics approach to studying Blastocystis. FEMS Microbiol Ecol 91: fiv072.

31. Alfellani MA, Stensvold CR, Vidal-Lapiedra A, Onuoha ESU, Fagbenro-Beyioku AF, Clark CG, 2013. Variable geographic distribution of Blastocystis subtypes and its potential implications. Acta Trop 126: 11-18.

32. Ramírez JD et al., 2016. Geographic distribution of human Blastocystis subtypes in South America. Infect Genet Evol 41: 32-35.

33. Yakoob J, Jafri W, Jafri N, Khan R, Islam M, Beg MA, Zaman V, 2004. Irritable bowel syndrome: in search of an etiology: role of Blastocystis hominis. Am J Trop Med Hyg 70: 383-385.

34. Ramírez JD, Flórez C, Olivera M, Bernal MC, Giraldo JC, 2017. Blastocystis subtyping and its association with intestinal parasites in children from different geographical regions of Colombia. PLoS One 12: 1-13.

35. Naceanceno KS, Matamoros G, Gabrie JA, Gabrie JA, Bottazzi ME, Sanchez A, Sanchez A, Mejia R, Mejia R, 2020. Use of multi-parallel real-time quantitative pcr to determine Blastocystis prevalence and association with other gastrointestinal parasite infection in a rural honduran location. Am J Trop Med Hyg 102: 1373-1375.

36. Commission on Social Determinants of Health, 2009. Closing the Gap in a Generation: Health Equity through Action on the Social Determinants of Health: Final Report: Executive Summary. Geneva, Switzerland: World Health Organization. doi: 10.1016/ j.respe.2009.04.006.
37. Bayer AM, Hunter GC, Gilman RH, Cornejo Del Carpio JG, Naquira C, Bern C, Levy MZ, 2009. Chagas disease, migration and community settlement patterns in Arequipa, Peru. PLoS Negl Trop Dis 3: e567.

38. Cociancic P, Torrusio SE, Zonta ML, Navone GT, 2020. Risk factors for intestinal parasitoses among children and youth of Buenos Aires, Argentina. One Health 9: 100116.

39. Tan KSW, 2004. Blastocystis in humans and animals: new insights using modern methodologies. Vet Parasitol 126: 121-144.

40. Villamizar X, Higuera A, Herrera G, Vasquez-A LR, Buitron L, Muñoz LM, Gonzalez- CFE, Lopez MC, Giraldo JC, Ramírez JD, 2019. Molecular and descriptive epidemiology of intestinal protozoan parasites of children and their pets in Cauca, Colombia: a cross-sectional study. BMC Infect Dis 19: 1-11.

41. Noradilah SA, Lee IL, Anuar TS, Salleh FM, Abdul Manap SNA, Husnie NS, Azrul SM, Moktar N, 2017. Blastocystis spp. contaminated water sources in aboriginal settlements. Trop Biomed 34: 110-117.

42. Skotarczak B, 2018. Genetic diversity and pathogenicity of Blastocystis. Ann Agric Environ Med 25: 411-416.

43. Martinez-Hernandez F, Martinez-lbarra JA, Lopez-Escamilla E, Villanueva-Garcia C, Muñoz-Garcia Cl, Rendon-Franco E, Maravilla $\mathrm{P}$, Villalobos $\mathrm{G}, 2020$. Molecular genotyping of Blastocystis spp. in wild mammals from Mexico. Parasitol Res 119: 97-104.

44. Franco RG, de Oliveira-Silva MB, Pedrosa AL, Nogueira GA, Cabrine-Santos M, 2018. Occurrence of Blastocystis spp. in domestic animals in triângulo mineiro area of Brazil. Rev Soc Bras Med Trop 51: 240-243.

45. Udonsom R, Prasertbun R, Mahittikorn A, Mori H, Changbunjong T, Komalamisra C, Pintong AR, Sukthana Y, Popruk S, 2018. Blastocystis infection and subtype distribution in humans, cattle, goats, and pigs in central and western Thailand. Infect Genet Evol 65: 107-111.

46. Levy MZ, Bowman NM, Kawai V, Waller LA, Geny J, Benzaquen EC, Gilman RH, Bern C, 2006. Periurban Trypanosoma cruziinfected Triatoma infestans, Arequipa, Peru. Emerg Infect Dis 12: $1345-1352$. 